of Bennett. We shall have more to say concerning the condition of this court.

The St. Patrick's Festival Dinner of the Irish Medical Schools' and Graduates' Association will be held at the Hotel Oecil on Saturday, March 16th (St. Patrick's Day falling this year on Sunday), at 7.15 P.M., the President, Dr. William Alexander, in the chair. Applications for tickets should be made without delay to Dr. J. Hutchinson Swanton, honorary secretary to the Dinner Committee, 40, Harleystreet, W.

The King, as Sovereign Head and Patron of the Order of St. John of Jerusalem in England, has approved the election by the Chapter-General of His Royal Highness the Duke of Cornwall and York, K.G., Sub.Prior of the Order, to the office of Grand Prior, vacant by His Majesty's resignation.

OWING to an epidemic of infectious disease, presumed to be influenza, which is prevailing on board H.M.S. training-ship Britannia the cadets were on March 2nd sent home for a period of three weeks.

Mr. G Leslie Eastes, M.B., B.Sc. Lond., who has been Laboratory Director of the Clinical Research Association, Limited, having vacated that post, has opened a laboratory for similar work at 62, Queen Anne-street, W.

- His Majestry tae KIng has signified to the President and Council of the Marine Biological Association his pleasure in becoming the patron of the association.

DR. HENRY WARD IRVINE has announced his retirement from the post of consultant to the Birmingham Consultative Medical and Surgical Institution.

\section{THE YESTERDAY AND TO-DAY OF AURAL SURGERY.}

By Sir William Dalby, F.R.C.S. ENG., \&c.

THE rapidity with which events in any department of surgery crowd upon each other and engross the attention of those who practise our art leaves little time for reflection, but it may not be altogether useless sometimes to pause for a few moments and consider, not only the extraordinary changes which have taken, and are taking, place, but the influence which such changes may be expected to have on the future. After the foundation of the Otological Society of the United Kingdom, which did me the honour of electing me President, the first meeting was held on Feb. 5th, 1900. Subsequently all the meetings were largely attended, the interest never for a moment flagged, and there was more material (all of which was most valuable) than could be presented and discussed. Finally, after the session the Transactions were published.

Not so many years ago it was a prevalent idea amongst surgeons that there was not a great deal of surgery in aural surgery, and that those who practised it were chiefly, if not entirely, engaged in endeavouring to give relief to the symptoms of deafness, tinnitus, and pain in the districts within and around the ear. If any such person is alive at the present moment-and I make no doubt that there are manylet him read those Transactions to which I have referred. He will there find some 30 contributions. Most of the cases were shown, submitted to the careful examination of the members present, and discussed most thoroughly. Anyone who reads these Transactions will find nothing but modern surgery and pathology, and throughout the whole volume hardly a mention (beyond what was incidental to the cases) of deafness or tinnitus. In short, the gravity of the cases in regard to life hardly permitted more than a passing attention to these symptoms. The time of the meetings was chiefly taken up in discussing cases of cerebellar abscess recently operated on, cholesteatoma removed from mastoid and meatus, thrombo-phlebitis of lateral sinus, adenosarcoma removed, ossicles removed for long-standing suppuration, complete mastoid operation, papillomatous growths removed, epithelial grafting of the labyrinth after removal of the semi-circular canals, sarcoma of the temporal bone, epithelioma of the meatus, \&c.

Surely in this list, which might be enlarged, there was no lack of surgery except that sort of surgery which was supposed to engage the attention (to the exclusion of all else) of the aural surgeon. A not altogether unnatural conclusion to which the reader might arrive is that the aural surgeons were so much engaged in, and so fascinated by, the operative surgery that has been mentioned that they had no time or inclination to bestow to what, after all, the multitude is seeking, the relief of deafness which so interferes with their occupations, their careers, their pleasures, and their happiness. Now this would be an assumption not in accordance with facts. It should be borne in mind that for many years past aural surgeons have been working incessantly and bestowing the most unremitting attention to the pathology of the changes which take place within the middle ear with a view, not only to their remedy, but their arrest and the protection against their advent, in this latter direction, especially in the case of childhood and early life, as our records, our daily practice, and results will show, with remarkable success. Let it be also remembered that nothing but the most laborious attention to details and the most careful watching of minute changes has effected this-so laborious that it has required faith in the possibilities that might follow to sustain the workers. One bit of knowledge (she fruit of experience) must always be present to the mind of the aural surgeon who intends to succeed with his cases, and this is that the most minute variations which are extraordinarily apt to escape the notice of a not very earnest observer make all the difference between bad and good hearing. This applies with especial force to middle-ear troubles, but in a measure also to nervous ones.

The surgery which our Transactions have displayed is no doubt very attractive. It is conceivable then, I repeat, that the reader might be led to think it possible that the more work a surgeon of this sort gets the less inclined he may be to trouble himself about the more wearisome and oftentimes disappointing though numerous cases in which the results are not so striking and life-saving. As one who has borne the burden and heat of the day I may be forgiven for assuming for the moment the position of the reader who asks this question and for sounding a note, not of warning, but rather of suggestion, to those who may be thinking of adopting a speciality the advancement of which has been the chief object of my life for some years. If it were necessary to do so 1 could point out endless examples in which nothing but the expenditure of a great deal of labour can teach the observer the best treatment of minor troubles and give him the delicacy in manipulation that is so necessary and so appreciated by the patient. Again, notwithstanding all the failures that have attended intra-tympanic operations preceded by incision of the membrane for the relief of obstruction within the tympanic cavity; notwithstanding that at some periods incision of the membrane was largely practised, at others given up (except in acute cases to let out pus), only to be revived again and again discontinued, the problem of relieving labyrinthine pressure will, I believe, some day be solved. Those who share this view with me will gain a ray of hope on reading in the Transactions a case by Mr. C. A. Ballance in which, when removing portions of dead bone from the petrous bone, "the semicircular canals were in part destroyed and the back of the vestibule opened." Later, after epithelial grafting operation, the hearing, which had been absent since childhood (there had been otorrhcea and mastoid disease), returned.

Whilst, therefore, I cannot but think that the reading of our Transactions will be a revelation to some as to the work which has been done, and so interesting a revelation that $I$ venture to recommend their perusal, I should much regret if an impression should arise that any part of the province of aural surgeons was in danger of being neglected by our members, so I have anticipated the possible suggestion that may arise in order to combat it and dismiss it as unterable. 